\section{What is the most important thing in the world?}

\author{
Hamish Robert Osborne
}

He tangata, he tangata, he tangata It is the people, it is the people, it is the people

Welcome to the Australasian College of Sport and Exercise Physicians (ACSEP) edition of BJSM. He tangata-it is the people in our lives that are important to us. How our two countries have managed the pandemic affecting the lives of the people around us will be told in stories for generations. Many more stories that affect our people are unfolding in front of us-not the least of which includes the warmest winter on record in Aotearoa New Zealand.

There are 68 people who have authored articles in this edition of BJSM! It would be great to highlight them all. Dr Richard Weiler and a truly international collaboration of experts have developed an important position statement on concussion for those involved with Para sport (see page 1187). This will help clinicians and healthcare providers identify concussion, treat athletes and improve health outcomes for the many Para sports where concussion occurs.

Dr Maurice Douryang (see page 1185) outlines the challenges faced in Cameroon to develop a flourishing Sport and Exercise Medicine (SEM) research community while embracing traditional cultural beliefs. Despite the success of its national football team, this Central African country requires a much improved infrastructure to enhance SEM educational and research pathways.

Medicine, University of Otago Dunedin School of Medicine, Dunedin, New Zealand

Correspondence to Dr Hamish Robert Osborne, Medicine, University of Otago Dunedin School of Medicine, Dunedin 9054, New Zealand;

hamish.osborne@otago.ac.nz
Dr Daniel Friedman et al (see page 1184) write a salient piece on overimaging, overdiagnosing and overtreating. All of these have the potential to harm and unfortunately have been largely driven by the SEM profession. A major U-turn in the space is needed. Along with harms, overimaging/diagnosis/treatment leads to perpetuation of health inequities in groups where systemic racism has led to poor health outcomes. These groups are often undertreated, but simply increasing access to more imaging which may be inappropriately driving overdiagnosis and overtreatment only worsens the inequity.

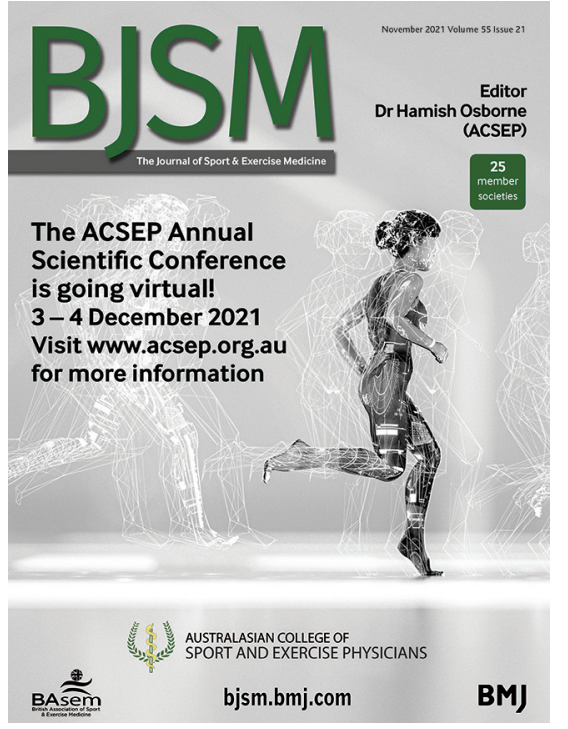

Dr Nonhlanhla Mkumbuzi et al (see page 1183) highlight the inequities resulting from the dearth of African female athletes represented in SEM research. It is clear that moving forward, gender and ethnicity should be front and centre in reporting and analysis. African women must be enabled to help provide answers that are relevant to them.
Whaiwhia te kete màtauranga

Fill the basket of knowledge

If you are looking for an online resource to keep you up to date, the SEM Academy (https://semacademy.org) is the most comprehensive resource for SEM education worldwide; managed by the ACSEP with content experts from across the globe. The Academy will ensure you are at the forefront of SEM education. If you are looking for a live interactive experience, join us at our Virtual Scientific Conference 'Ahead of the Game' on 3 and 4 December 2021. Check out details at https:// wwwacseporgau.

Waiho i te toipoto, kaua i te toiroa

Let us keep close together, not wide apart

While social distancing has become the norm and opportunities to meet face-toface to discuss our work have become limited, we hope that this ACSEP edition of BJSM gives you an opportunity to reconnect and to think about not only the people who do the research but the communities we aim to help.

Twitter Hamish Robert Osborne @Hamish_Osborne Contributors I wrote it all.

Funding The authors have not declared a specific grant for this research from any funding agency in the public, commercial or not-for-profit sectors.

Competing interests None declared.

Patient consent for publication Not required.

Provenance and peer review Commissioned; internally peer reviewed.

(C) Author(s) (or their employer(s)) 2021. No commercial re-use. See rights and permissions. Published by BMJ.

A) Check for updates

To cite Osborne HR. Br J Sports Med 2021;55:1181.

Accepted 14 September 2021

Br J Sports Med 2021;55:1181.

doi:10.1136/bjsports-2021-104937

ORCID iD

Hamish Robert Osborne http://orcid.org/0000-00024265-4833 